\title{
High-quality Finishing Process for Silicon Carbide Optical Components Using Conventional Equipment
}

\author{
Marcos Valentim Ribeiro dos Santos ${ }^{a, b *}$ (D), Alvaro José Damião ${ }^{a, b}$, Antonio Jorge Abdalla ${ }^{b}$ \\ anstituto Tecnológico de Aeronáutica, Praça Marechal Eduardo Gomes, 50, 12228-900, São José dos \\ Campos, SP, Brasil. \\ ${ }^{b}$ Instituto de Estudos Avançados, Trevo Coronel Aviador José Alberto Albano do Amarante, 01, \\ 12228-001, São José dos Campos, SP, Brasil.
}

Received: August 20, 2021; Revised: November 01, 2021; Accepted: December 08, 2021

\begin{abstract}
The development of low-cost high quality surface finishing methods for silicon carbide ( $\mathrm{SiC}$ ) is an arduous task. Nowadays, the $\mathrm{SiC}$ mirrors manufacture involves extensive, complex, and costly finishing processes carried out on highly expensive ultra-precise machines. In this work, a cost-effective surface finishing method has been successfully developed, using conventional machines for the optical finishing of $\mathrm{SiC}$. The results showed that the combination of ductile grinding and polishing in conventional low-cost machines allowed to obtain high-quality surface finish on $\mathrm{SiC}$ substrates with low roughness (4-10 $\mathrm{nm} \mathrm{Ra}$ ) and optical figure in the range $\lambda / 4-\lambda / 8$, at a reduced 32 hours total processing time.
\end{abstract}

Keywords: Silicon carbide, machining, polishing, roughness, optical figure.

\section{Introduction}

Compared to conventional glasses and metals, silicon carbide $(\mathrm{SiC})$ is an excellent substrate for high-performance optical applications due to its high specific stiffness, high thermal conductivity, and superior dimensional stability ${ }^{1,2}$. It is considered the preferred material in manufacturing lightweight mirrors for aeronautical and aerospace uses ${ }^{3}$.

Low roughness (tens of nanometers) and small optical figures $(\lambda / 4$ or $\lambda / 8)$ are essential attributes for high-quality flat mirrors ${ }^{4}$.

Due to extreme hardness and brittleness, material removal rates for $\mathrm{SiC}$ are very low, around $1 / 35^{\text {th }}$ that of fused silica and less than $1 / 50^{\text {th }}$ that of Zerodur ${ }^{1}$. Different techniques and technologies ${ }^{1,3,5}$ have been used to produce $\mathrm{SiC}$ substrates close to the final dimension in order to reduce their post-processing, due to the complexity of the finishing process, generally carried out by diamond wheel grinding in expensive ultra-precise machines ${ }^{6-9}$. In ceramics grinding, the process of material removal by brittle fracture predominates ${ }^{10}$. However, from observations in micro-indentation tests, ductile machining of brittle materials has been reported ${ }^{11,12}$. In the ductile grinding process, the mechanism of material removal occurs by plastic flow. As a result, smooth, uniform surfaces and no grinding-induced damages or subsurface fractures are obtained ${ }^{13}$. Often, the machined surface is characterized by parallel lines called ductility streaks, and the subsequent polishing process takes place in less time and with a better result for the surface finish ${ }^{14}$.

The current technology for ductile grinding of brittle materials dates back to the 1990's, with Blackley and Scattergood $^{15}$, Bifano and Fawcett ${ }^{13}$, Malkin and Hwang ${ }^{12}$, and later, in the 2000's, with Mamalis et al. ${ }^{10}$ and even today, it is a field of studies in full development. More

*e-mail: valentim75@yahoo.com.br recently, Meng et al. ${ }^{16}$ used scratching simulation to study the influence of the $\mathrm{SiC}$ microstructure on the grinding process. Sanjay ${ }^{17}$ has developed analytical models for $\mathrm{SiC}$ machining from the experimental study of parameters, such as depth of cut, feed rate, size, and proportion of grains in the grinding wheel.

Bifano et al. ${ }^{18,19}$ established a model based on the critical depth of cut by studying glasses, single crystals, and advanced ceramics grinding. According to the authors, for any material, if the dimensional scale of material removal is made small enough, material removal runs by a mechanism of plastic flow and not by fracture. The study showed that in ultra-precise machines, the practice of cutting depths at a scale as small as tens of nanometers allows machining with material removal by plastic flow, thus combining the dimensional control inherent in the grinding processes with the super-finishing of typical polishing surfaces. As in ductile grinding, polishing is performed by plastic material removal. This plasticity is responsible for the formation of a uniform and smooth surface ${ }^{19}$. In classic polishing processes, the material removal happens by chemical and mechanical interactions between the abrasive (typically cerium oxide or aluminum oxide powders), the carrier fluid (water), and the workpiece $^{20}$. It is a time-consuming and non-deterministic process.

According to established theory, conventional machines cannot produce a high-quality finish on hard and brittle materials such as ceramics. This is mainly due to the conventional machines' low precision in controlling fundamental parameters such as material removal rate, depth of cut, feed rate, cutting speed, and a consequent excessive load of abrasive grains on the workpiece surface ${ }^{9,19}$.

For SiC optical finishing, the cutting-edge technology uses expensive interferometers coupled with ultra-precise 
CNC surface finishing machines ${ }^{1-3,6}$. Workpieces with low roughness $(R \mathrm{a}<10 \mathrm{~nm})$ and optical figure quality in the range $\lambda / 4-\lambda / 10$ are obtained. On the other hand, the high-cost effectiveness is still prohibitive to fully realizing the ceramic's potential ${ }^{7,17,21}$.

The innovative contribution of this work was to show the feasibility of the SiC optical finishing using conventional equipment. The importance this cost-effective and high-quality processing method was the combination of a controlled ductile grinding and a polishing on low-cost machines to obtain optical figures and roughness values comparable to state-of-the-art results with reduced time processing for brittle materials.

\section{Material and Methods}

\subsection{Raw materials}

Two phases of polycrystalline $\mathrm{SiC}$ were used in this study: the $\beta$-SiC and $\alpha$-SiC. One raw material used in this study was $\beta$-SiC ballistic armor plates $(64 \mathrm{~mm} \times 64 \mathrm{~mm} \times 16 \mathrm{~mm})$ produced by the Materials Division of the Brazilian Department of Aerospace Science and Technology - DCTA. The other raw material was $\alpha$-SiC sintered from $\beta$-SiC Grade BF $17 \mathrm{SiC}$ powder (H. C. Starck, Germany), adding $7.6 \%$ by weight of $70 \% \mathrm{Al}_{2} \mathrm{O}_{3}$ Type A1000 SG (ALCOA, Brazil) and 30\% $\mathrm{Y}_{2} \mathrm{O}_{3}$ Type GRADE C (FINE) (H. C. Starck, Germany). The raw materials were blended in deionized water with $50 \%$ liquids using 1.5 wt. \% of Lancol RH, 1 wt. \% of PVA (polyvinyl alcohol) Airvol 205 and 0.2 wt. \% of Disperlan LA (Lambra) as a lubricant, binder, and dispersant, respectively. After milling for 24 hours in a ball mill, the mixture was dried, sieved, and pressed in a steel die at $38 \mathrm{MPa}$ uniaxial pressing load. Subsequently, the green samples were pressed isostatically at $300 \mathrm{MPa}$. Sintering took place in two stages: pre-sintering at $900^{\circ} \mathrm{C}\left(1^{\circ} \mathrm{C} / \mathrm{min}\right.$ heating rate $)$ for 1 hour, and final sintering in a tube furnace with an inner lining of graphite at $1950^{\circ} \mathrm{C}\left(30^{\circ} \mathrm{C} / \mathrm{min}\right.$ heating rate $)$ for $30 \mathrm{~min}$, in an argon atmosphere. The final test workpiece's dimensions were $19 \mathrm{~mm}$ in diameter $\mathrm{x} 5 \mathrm{~mm}$ thick.

\subsection{Conventional optical glass milling machine HKM 63}

The grinding happened in a conventional optical glass milling machine (Carl Zeiss Jena, HKM 63 Model) with a metal bond diamond cup grinding wheel Type: 2M2-180-5-4/D126/BZ560/C100 (FEPA/Winter specifications) of $180 \mathrm{~mm}$ in diameter and $5 \mathrm{~mm}$ in width. Figure 1 shows the operation scheme of the HKM 63 machine used in all steps of the study.

The SiC workpieces are fixed with a vegetable pitch on an aluminum plate and attached to the machine. The grinding wheel advances in the longitudinal direction until it smoothly touches the surface workpieces. The movements are locked, and the desired depth of cut is practiced. The workpieces rotate at low speed, and for a predetermined time, successive passages of the workpieces occur against the cutting tool that rotates at high speed. The process is refrigerated by ethylene-glycol 5\% in a water solution.

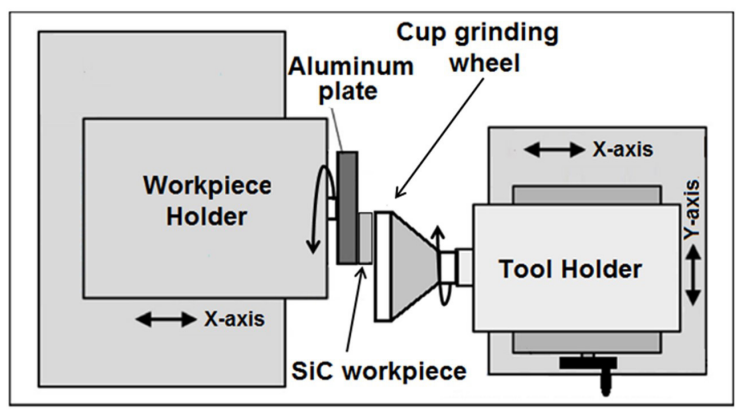

Figure 1. Scheme of the HKM 63 machine operation.

\subsection{Polishing equipment and dedicate polishing toll}

The polishing was performed using a conventional polishing machine ( $\mathrm{LOH}$, model PM-250) with $0.25 \mu \mathrm{m}$ diamond paste diluted in a water and glycerin solution. The polishing tool was assembled with laminated polyurethane foam on a cast iron plate. Figure 2 shows the sequence for the assembly of the polishing tool.

The polishing tool was manufactured to maximize the abrasive effect when polishing and correcting the deviation in the shape of the machined workpieces.

In (a), the machined workpieces are measured with the flat polishing gauge after final grinding. In (b), the cast iron plate surface is assessed. Based on the values of the shape deviation of the machined workpieces, the diamond pellets on the smoothing block ground the cast iron plate's surface and give the desired deviation to the surface. In (c), the polyurethane foam is deposited on the cast iron, shaping it on the plate. Polyurethane was applied to the plate without any bonding since the thickness of the adhesive layer could interfere with the relief of the plate and change the initial planned conditions for polishing. The action of glycerin in the interface (polishing pad/cast iron plate) combined with the pressure of the pieces along the polishing was sufficient to keep the polyurethane fixed on the plate.

Along with the study, the roughness was measured with a Talysurf GPI 1000 Taylor Hobson profilometer. The flatness by an MK TV XP-4500 Zygo interferometer and the surfaces were analyzed by light microscopy using the Axio Imager A2 Zeiss microscope.

\subsection{Methods}

The study was carried out in three steps, as summarized in Table 1 .

In Step 1, the whole $\beta$-SiC ballistic armor plate was used to check the feasibility of conventional grinding. The operational characteristics of the grinding machine are presented in Table 2.

Table 1. Operating sequence for experimental processing of substrates.

\begin{tabular}{|c|c|c|c|}
\hline Step & Operation & Aim & Substrates \\
\hline 1 & Grinding & Feasibility & $\beta-\mathrm{SiC}$ \\
\hline 2 & Grinding & $\begin{array}{c}\text { Process } \\
\text { optimization }\end{array}$ & $\alpha-\mathrm{SiC}$ \\
\hline 3 & $\begin{array}{l}\text { Grinding/ } \\
\text { polishing }\end{array}$ & Final finishing & $\alpha-\mathrm{SiC}$ and $\beta-\mathrm{SiC}$ \\
\hline
\end{tabular}



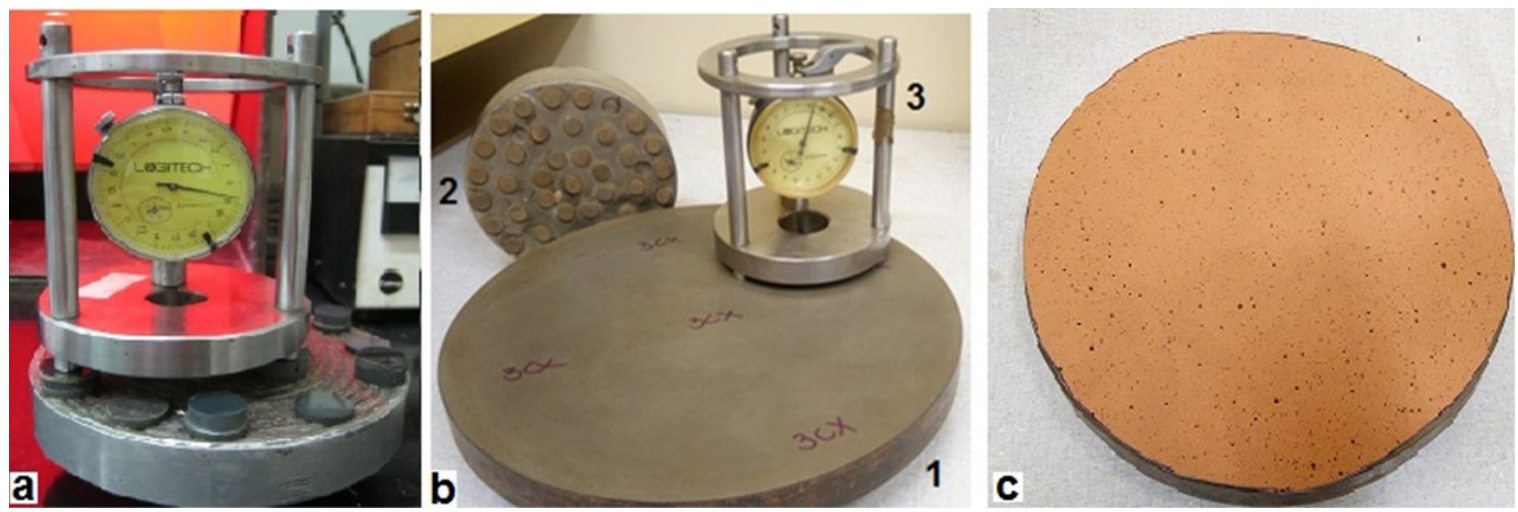

Figure 2. a) Measurement of machined workpieces; b) 1-Cast iron plate. 2-Logitech diamond smoothing block 5 " in diameter composed of pellets with $40 \mu \mathrm{m}$ diamond grains attached to the base. 3-Logitech flat polishing gauge model 1SDG1. c) Polyurethane foam on the plate.

Table 2. Capabilities of HKM 63 machine.

\begin{tabular}{ccc}
\hline Depth of cut $\boldsymbol{a}_{\boldsymbol{p}}(\boldsymbol{\mu \mathrm { m } )}$ & Grinding wheel speed $\boldsymbol{v}_{\boldsymbol{s}}(\mathbf{m} / \mathbf{s})$ & Workpiece rotation (RPM) \\
\hline 10 & $23-32-47-64$ & $0.56-1.1-1.7-3.4$ \\
\hline
\end{tabular}

The Bifano's critical depth of cut model uses an approximate fracture mechanism developed from indentation studies and data from studies generated in diamond grinding tests. The critical depth of cut to start a fracture is given by the equation:

$$
\boldsymbol{d}_{\boldsymbol{c}}=0.15\left(\frac{\boldsymbol{E}}{\boldsymbol{H}}\right)\left(\frac{\boldsymbol{K}_{\boldsymbol{c}}}{\boldsymbol{H}}\right)^{2}
$$

where $H$ is the hardness, $E$ is the elastic modulus, and $K_{c}$ is the fracture toughness.

The choice of processing parameters was determined based on the value of the critical cutting depth $d$ for which it is possible to material removal by plastic flow, i.e., ductile grinding ${ }^{19}$. Based on values reported by the literature on the mechanical properties of $\mathrm{SiC}^{22}: E=460 \mathrm{GPa}, H=26 \mathrm{GPa}$, and $K_{c}=3.5 \mathrm{MPa} \mathrm{m} 1 / 2$. From Equation 1 , the calculated $d c$ value for ductile grinding is $48 \mathrm{~nm}$. The smallest possible depth of cut in the conventional equipment used in the study exceeds 208 times the value needed for ductile grinding. Considering the extreme hardness and fragility of $\mathrm{SiC}$, the processing parameters chosen to start the feasibility test were the lowest possible to be practiced on the equipment. The value of the parameters was gradually increased until the equipment's machining limit was reached. Thus, three grinding wheel speeds $(23 \mathrm{~m} / \mathrm{s}, 32 \mathrm{~m} / \mathrm{s}$, and $47 \mathrm{~m} / \mathrm{s})$ and three depths of cut $(10 \mu \mathrm{m}, 25 \mu \mathrm{m}$, and $50 \mu \mathrm{m})$ were tested. The rotation of the workpieces was maintained at 0.56 RPM and the grinding time at $30 \mathrm{~min}$. The best parameters obtained at the feasibility test were applied then to the $\beta$-SiC plates grinding. The grinding period was extended to 4 and 6 hours to evaluate the possible occurrence of plastic flow, with a reduced grinding scale (ductile grinding), as reported by Bifano $^{18}$.

The aim of Step 2 was the grinding optimization, also using the best parameters of Step 1. The $\alpha$-SiC disks (19 mm diameter $\times 5 \mathrm{~mm}$ thick) was attached to an aluminum plate with a vegetable pitch. The roughness was evaluated after 6 hours of machining time. Evaluations were made quantitatively using the profilometer.

In Step 3, grinding and polishing procedures were tested from rough surface $(>5 \lambda)$ to the final finishing $(\lambda / 4$ or $\lambda / 8$ expectation). Disks $21 \mathrm{~mm}$ diameter x $5 \mathrm{~mm}$ thick cut from another $\beta$-SiC ballistic armor plate were attached with rough $\alpha$-SiC disks to the aluminum plate. Grinding time was extended still further (from $6 \mathrm{~h}$ to $8 \mathrm{~h}$ ), aiming to extremely low roughness (few nanometers expectation), and the polishing time was 24 hours.

\section{Results and Discussion}

\subsection{Step 1: grinding of the $\beta$-SiC plates: feasibility test}

Visual inspection of the micrographs (Figure 3) revealed that the ground surface was rough, typical of brittle mode grinding, without ductile streaks. At both speeds $(23 \mathrm{~m} / \mathrm{s}$ and $32 \mathrm{~m} / \mathrm{s}$ ) and at $a_{p}=25 \mu \mathrm{m}$, the images revealed typical brittle fracture damages in the surface, as shown in Figure $3 \mathrm{a}$ and $3 \mathrm{c}$. At $32 \mathrm{~m} / \mathrm{s}$ and $10 \mu \mathrm{m}$, grinding was also in the brittle mode (Figure $3 \mathrm{~b}$ ), and at the lower speed and lower depth of cut condition $\left(v_{s}=23 \mathrm{~m} / \mathrm{s}\right.$ and $\left.a_{p}=10 \mu \mathrm{m}\right)$, surface damage was significantly reduced, as display in Figure $3 \mathrm{~d}$.

On the other hand, after a few seconds machining at $47 \mathrm{~m} / \mathrm{s}$, the plate has broken by overheating, whatever the depth of cut. Figure 4 presents surface images of the $\beta-\mathrm{SiC}$ plate machined at $10 \mu \mathrm{m}$. In Figure $4 \mathrm{a}$, the arrows indicate damage related to the circular trajectory described by the abrasive grains attached to the cup grinding wheel along with the $\beta$ SiC plate. Sectors A and B were evaluated by light microscopy. In Figure 4b, sector A micrograph has shown three distinct regions, which correspond to the three material removal modes: 1-ductile, 2-brittle, and 3-ductile-brittle 

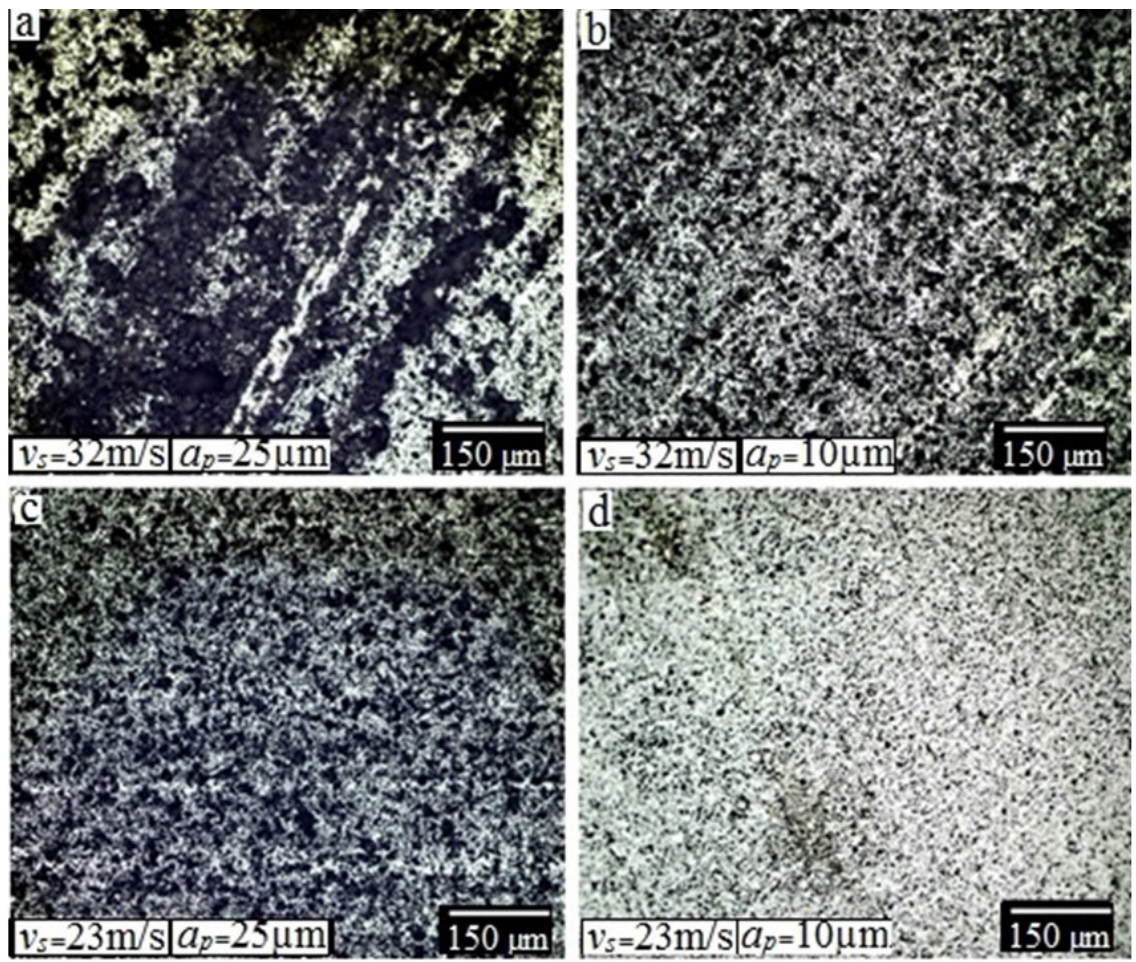

Figure 3. Light micrographs of surface characteristics for $23 \mathrm{~m} / \mathrm{s}$ and $32 \mathrm{~m} / \mathrm{s}$ grinding wheel speeds at $10 \mu \mathrm{m}$ and $25 \mu \mathrm{m}$ depth of cut. (scale bar $150 \mu \mathrm{m}$ ).
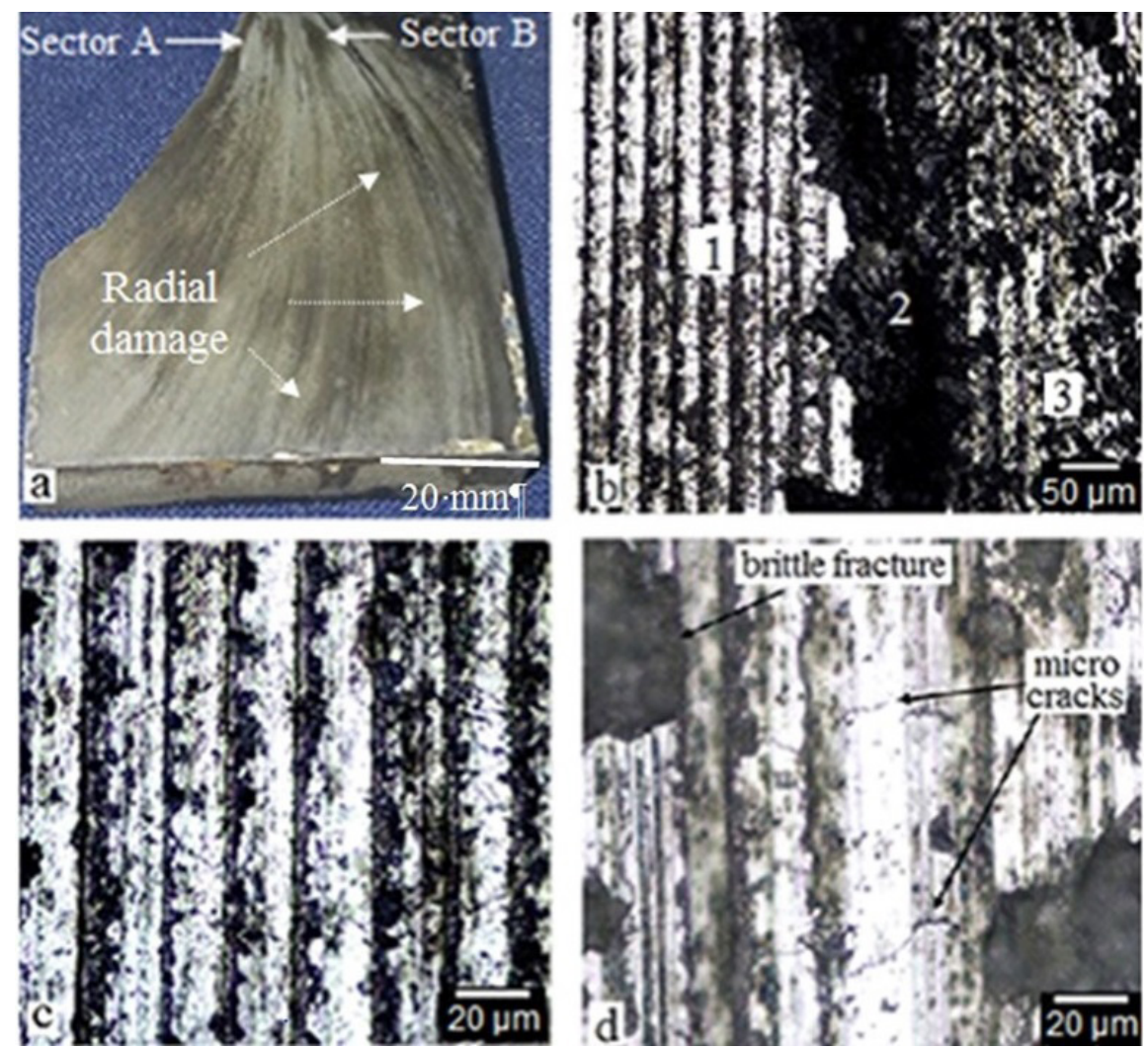

Figure 4. a) Photo of the $\beta$-SiC armor plate machined showing the sectors named A and B; (b) light micrographs of sector A; (c) region 1 of sector $\mathrm{A}$, and (d) sector $\mathrm{B}$. 
transition, according to Gu et al. ${ }^{23}$ and Zhong ${ }^{14}$. The presence of parallel lines in area 1 (magnified in Figure 4c) is a first indication that material was removed by plastic flow. These parallel lines are referred to as ductility streaks, typical of ductile mode machining ${ }^{14,18}$.

Table 3 summarizes the feasibility test results from step 1 .

It was inferred that grinding is feasible at the grinding speed $v_{s}=23 \mathrm{~m} / \mathrm{s}$, workpiece rotation $0.56 \mathrm{RPM}$, and depth of cut $a_{p}=10 \mu \mathrm{m}$. These feasible parameters were adopted in the next stages of this study to evaluate the influence of the time of machining.

In Figure 5, the images show of the $\beta$-SiC plate surface after grinding for 4 hours at this feasible condition. In addition to pores, inherent to the sintering process, characteristics streaks of plastic flow and ductile mode of material removal can be seen in Figure 5a, where widened and highly parallel streaks are evidenced. Compared with Figure 4c, the streaks width $(\sim 600 \mu \mathrm{m}$ wide) increased 30 times. In Figure 5b, the ground $\beta$-SiC plate's edge is exhibited, where neither radial scratches nor brittle fracture damage were observed.

It is interesting to note that the ductile streaks are parallel, equidistant, and concurrent. They were produced from the machining with a cup grinding wheel with circular geometry. There is a limited number of published works that used diamond cup wheels for optical grinding ${ }^{24}$. It is understood that the nature of the streaks printed on the ground surface needs to be further investigated.

After grinding for 6 hours, the $\beta$-SiC plate surface has acquired a specular appearance, as shown by the reflected image of a small gear placed on it (Figure 6). No evidence of ductility streaks was observed.

Bifano et al. ${ }^{18}$ reported that reducing the grinding scale as the machining progresses contributes to the transition of the material removal mode from brittle to ductile. The ductility streaks may have widened further or even completely removed by the material-removal mechanism by plastic flow from the reduction in the grinding scale.

\subsection{Step 2: grinding of $\alpha-S i C$ samples: process optimization}

Figure 7 shows $\alpha$-SiC samples before and after grinding for 2 and 6 hours. In Figure 7b, 2 hours grinding proved to be ineffective. The machined surface presented several damages by brittle fracture and radial marks caused by the abrasive grains of the grinding wheel. As observed in step 1, after 6 hours machining, specular reflection was obtained (Figure 7c). The ductile regime with significant roughness reduction was achieved by decreasing the grinding scale.

Table 3. Summary of the feasibility test results as a function of the different processing parameters.

\begin{tabular}{cccc}
\hline Grinding wheel speed $\boldsymbol{v}_{\boldsymbol{s}}(\mathbf{m} / \mathbf{s})$ & Depth of cut $\boldsymbol{a}_{\boldsymbol{p}}(\boldsymbol{\mu \mathbf { m } )}$ & Grinding time $(\mathbf{m i n})$ & Result \\
\hline \multirow{2}{*}{23} & 10 & 30 & Satisfactory \\
& 25 & 30 & Surface fractures \\
& 50 & - & Detachment/breakage \\
\hline \multirow{2}{*}{32} & 10 & 30 & Surface fractures \\
& 25 & 30 & Surface fractures \\
& 50 & - & Detachment/breakage \\
\hline \multirow{2}{*}{47} & 10 & - & Overheating/Breakage \\
\end{tabular}
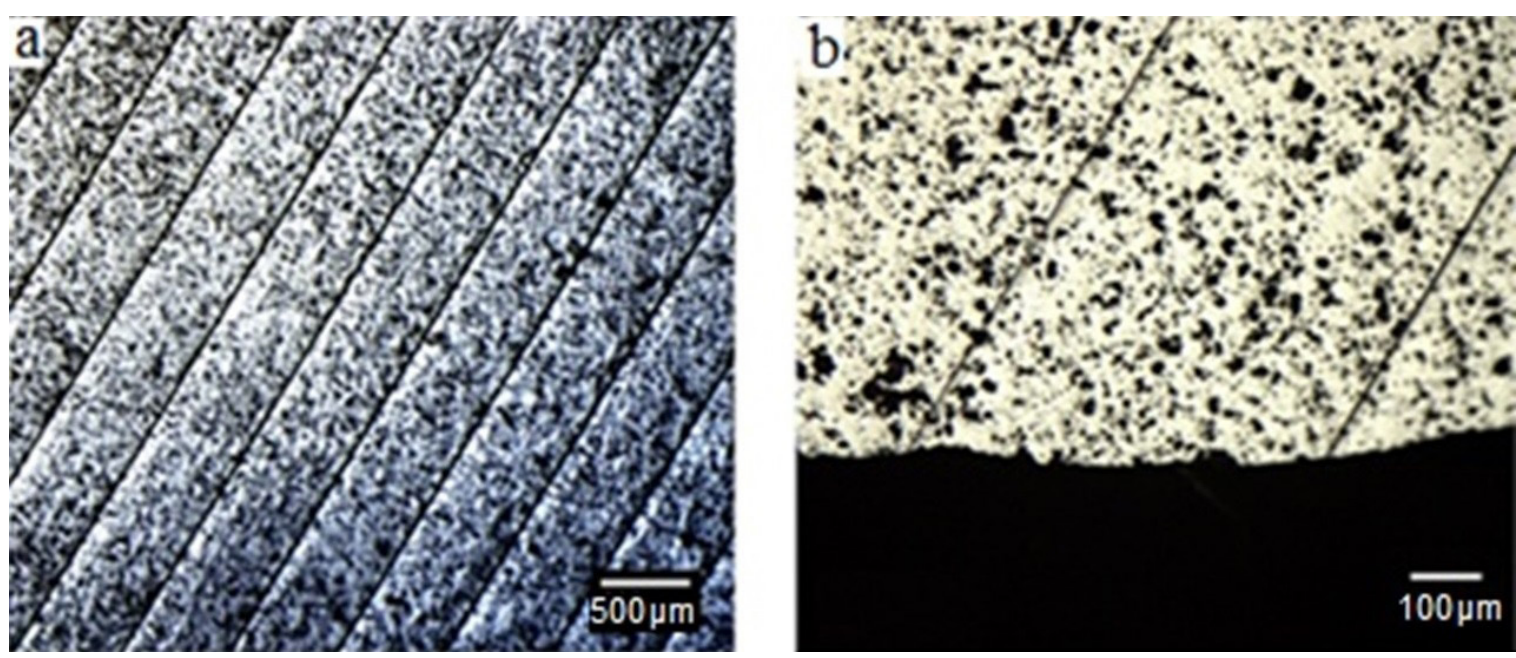

Figure 5. Light micrographs of the ductility streaks after $4 \mathrm{~h}$ of machining. 
Table 4 presents the $R$ a roughness measured as a function of the grinding time. Expressive reduction from $3380 \pm 50 \mathrm{~nm}$ to $37 \pm 4 \mathrm{~nm}$ was noted in $R a$ in this step.

Table 4. Measured Ra roughness as a function of the grinding time at $23 \mathrm{~m} / \mathrm{s}$ grinding wheel speed and $10 \mu \mathrm{m}$ depth of cut.

\begin{tabular}{cc}
\hline Roughness $\boldsymbol{R a}(\mathbf{n m})$ & Time (h) \\
\hline $3380 \pm 50$ & 0 \\
Brittle fracture damage & 2 \\
$37 \pm 4$ & 6 \\
\hline
\end{tabular}

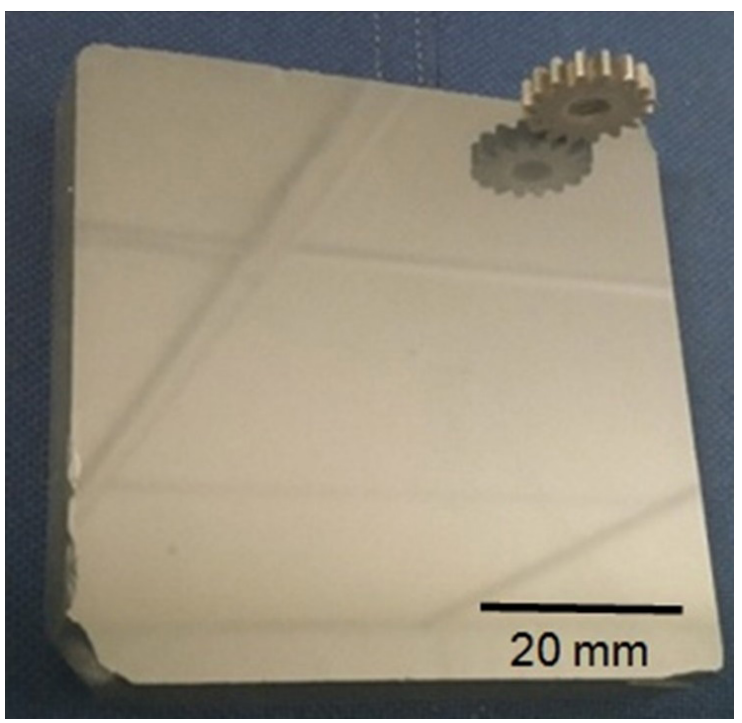

Figure 6. Photo of the specular finishing of the $\beta$-SiC plate machined.
The next step was the surface finishing for both the $\alpha-\mathrm{SiC}$ and the $\beta$-SiC samples.

\subsection{Step 3: grinding and polishing of $\alpha-S i C$ and \\ $\beta$-SiC workpieces: from rough to the final surface finishing}

New $\alpha$-SiC and $\beta$-SiC workpieces were attached to the aluminum plate. The pieces were numbered from 1 to $6(1,4$, and 6 are $\beta$-SiC; 2,3 , and 5 are $\alpha-\mathrm{SiC})$, as shown in Figure 8 . Sample 6 has its roughness evaluated throughout the whole machining process, while its optical figure has only been assessed at the end of the process.

Table 5 shows the roughness reduction over the machining time. The roughness value is compatible with the values found in step 2 for the same processing time. As machining progresses, the roughness value decreased significantly, reaching a minimum of $15 \pm 7 \mathrm{~nm}$ after 8 hours grinding. The peak-to-valley (PV) result achieved for the optical figure is equal to $1226 \pm 5 \mathrm{~nm}$.

After grinding, the $\beta$-SiC and $\alpha$-SiC substrates have exhibited an intrinsic convex surface, checked by a Logitech flat polishing gauge $(2.5 \mu \mathrm{m}$ bend radius above the plane). Considering that the material removal rates are lower for the $\mathrm{SiC}$ compared with the conventional optical materials ${ }^{1}$, the polishing device was manufactured with a $3 \mu \mathrm{m}$ convex curvature radius to correct machined workpiece's shape deviation and also to maximize the abrasive effect while polishing. The samples were polished at 40 RPM and $4 \mathrm{~N}$ load, varying the polishing time from 0 to $24 \mathrm{~h}$.

In Figure 9, the peak-to-valley deviation as a function of polishing time for the workpiece 6 curve is presented.
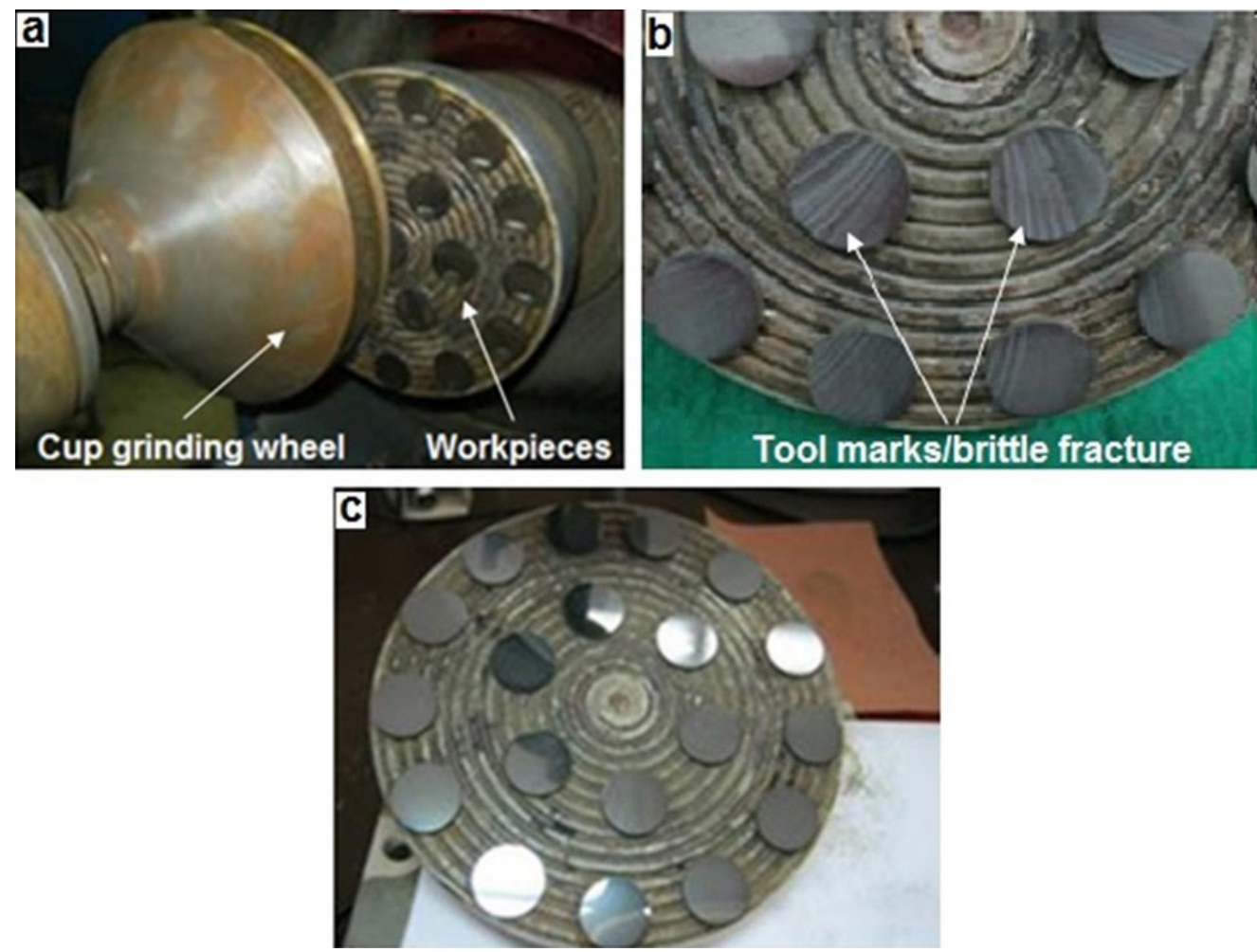

Figure 7. Photos of the aluminum plate with attached $\alpha$-SiC workpieces a) before grinding, and after grinding for (b) 2 hours, and (c) 6 hours. 


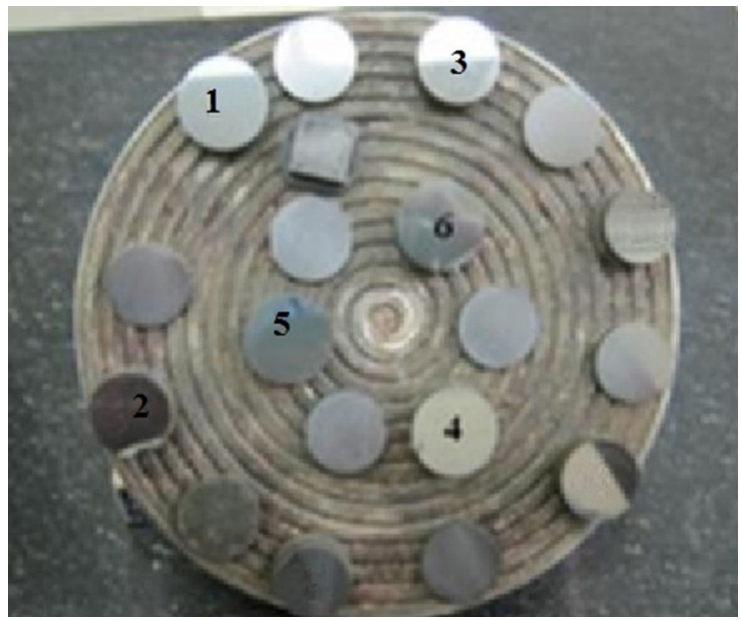

Figure 8. Photo of numbered workpieces of $\alpha-\mathrm{SiC}$ and $\beta$-SiC.

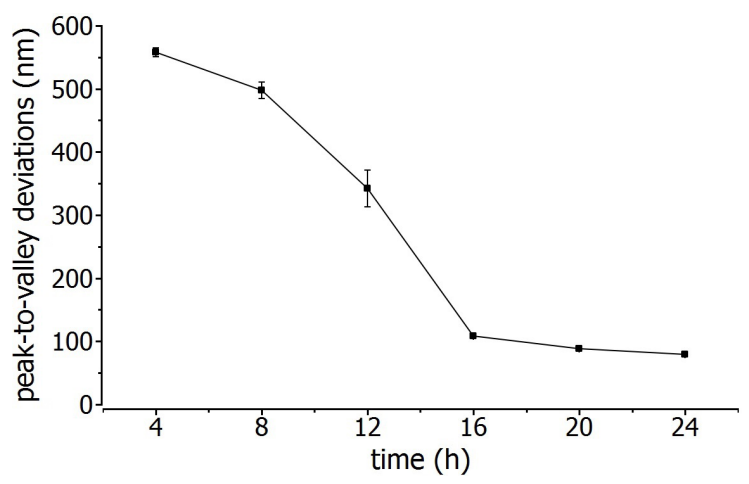

Figure 9. Peak-to-valley deviations as a function of polishing time for the workpiece 6 .

Table 5. Roughness data of sample 6 as a function of the machining time.

\begin{tabular}{cc}
\hline Machining time (h) & Roughness $\boldsymbol{R a}(\mathbf{n m})$ \\
\hline 0 & $3480 \pm 40$ \\
2 & Brittle fracture damage \\
6 & $40 \pm 16$ \\
8 & $15 \pm 7$ \\
\hline
\end{tabular}

Material removal was more significant at the first $16 \mathrm{~h}$ of polishing. The curve tended to plateau from $16 \mathrm{~h}$ to $24 \mathrm{~h}$, suggesting loss of effectiveness in polishing for more than $24 \mathrm{~h}$. However, surface quality was better than $\lambda / 8$ at $24 \mathrm{~h}$.

Table 6 shows the optical figure deviations for each workpiece after 8 hours machining, and the roughness and optical figure values for the finished workpieces, after 24 hours polishing. In all finished workpieces, low roughness expectation ( $\mathrm{a}$ a about tens of nanometers) and optical figure in the range $\lambda / 4-\lambda / 8$ were achieved.

According to the available literature ${ }^{9,19}$, conventional machines cannot produce $\mathrm{SiC}$ optical finishing, but the results obtained in this work are compatible with the ones obtained in ultra-precision equipment ${ }^{1,6,7}$.
Table 6. Peak-to-valley deviations after 8 hour machining, and finished surface $R$ a roughness, and peak-to-valley deviations after 24 hours polishing.

\begin{tabular}{ccccc}
\hline \multirow{2}{*}{ Workpiece } & $\begin{array}{c}\text { Machining } \\
\text { PV (nm) }\end{array}$ & & \multirow{2}{*}{$\boldsymbol{R a}(\mathbf{n m})$} & $\begin{array}{c}\text { Polishing } \\
\text { PV (nm) }\end{array}$ \\
\cline { 2 - 2 } \cline { 5 - 5 } & $\mathbf{8}$ hours & & \multicolumn{2}{c}{$\mathbf{2 4}$ hours } \\
\hline $1(\beta-\mathrm{SiC})$ & $1749 \pm 66$ & & $7.5 \pm 1.0$ & $133 \pm 1$ \\
\hline $4(\beta-\mathrm{SiC})$ & $1665 \pm 15$ & & $5.9 \pm 0.6$ & $95 \pm 1$ \\
\hline $6(\beta-\mathrm{SiC})$ & $1226 \pm 5$ & & $5.7 \pm 1.6$ & $79 \pm 2$ \\
\hline $2(\alpha-\mathrm{SiC})$ & $1546 \pm 51$ & & $6.4 \pm 0.6$ & $157 \pm 4$ \\
\hline $3(\alpha-\mathrm{SiC})$ & $1066 \pm 25$ & & $10.0 \pm 4.5$ & $156 \pm 1$ \\
\hline $5(\alpha-\mathrm{SiC})$ & $1102 \pm 17$ & & $4.0 \pm 1.0$ & $226 \pm 23$ \\
\hline
\end{tabular}

\section{Conclusions}

The development of a cost-effective and high-quality finish processing for $\mathrm{SiC}$ optical components using conventional equipment and techniques was accomplished.

In step 1, the best processing parameters were determined. At this best grinding condition, the workpieces were machined with $10 \mu \mathrm{m}$ cutting depth, which is much greater than the critical depth value $d c$ determined for ductile grinding $(48 \mathrm{~nm})$. But the reduction in the grinding scale as the machining progressed allowed material removal by plastic flow mechanism from 4 hours onwards. In step 2, grinding for 6 hours produced a specular reflective surface with expressive $R$ a reduction to $37 \pm 4 \mathrm{~nm}$. Effectiveness in grinding for more than 6 hours was verified.

In step 3, the whole process was rechecked. The $R \mathrm{a}$ roughness was lower than $20 \mathrm{~nm}$ and the optical figure, between $2 \lambda$ and $3 \lambda$ after $8 \mathrm{~h}$ machining. Using a polishing device designed to correct the shape deviation of machined workpieces, $R$ a roughness as low as $4-10 \mathrm{~nm}$ and an optical figure in the range $\lambda \backslash 4-\lambda \backslash 8$ were obtained.

Compared with the cutting-edge technology, which uses expensive, ultra-high precision machinery and a timeconsuming process, the machining process developed in this work is cost-effective with reduced processing time.

\section{Acknowledgment}

To the National Council for Scientific and Technological Development (CNPq - process number 301881/2015-4), and the Materials Division - AMR, the Institute of Aeronautics and Space - IAE, Department of Aerospace Science and Technology - DCTA, for the material supplied.

\section{References}

1. Johnson SJ, Grobsky K, Bray DJ. Rapid fabrication of lightweight silicon carbide mirrors. In: SPIE of the International Symposium on Optical Science and Technology; 2002; Seattle, WA, USA. Proceedings. USA: SPIE; 2002. Vol. 4771. p. 243-53. http:// dx.doi.org/10.1117/12.482166.

2. Wang $X$, Zhang $X$. Theoretical study on removal rate and surface roughness in grinding a $\mathrm{RB}-\mathrm{SiC}$ mirror with a fixed abrasive. Appl Opt. 2009;45:904-10. http://dx.doi.org/10.1364/ AO.48.000904.

3. Robichaud JL. SiC optics for EUV, UV, and visible space missions. Future EUV/UV and Visible Space Astrophysics Missions and Instrumentation. In: Astronomical Telescopes 
and Instrumentation Event; 2003; Waikoloa, Hawaii, USA. Proceedings. USA: SPIE; 2003. Vol. 4854. p. 39-49. http:// dx.doi.org/10.1117/12.459771.

4. Zhang J, Han L, Zhang J, Liu H, Yan Y, Sun T. Brittle-to-ductile transition in elliptical vibration-assisted diamond cutting of reaction-bonded silicon carbide. J Manuf Process. 2019;45:67081. http://dx.doi.org/10.1016/j.jmapro.2019.08.005.

5. Fruit M, Antoine P. Development of silicon carbide mirrors: the example of the Sofia secondary mirror. In: SPIE of the International Conference on Space Optics; 2000; Toulouse Labège, France. Proceedings. France, 2000. vol. 10569. http:// dx.doi.org/10.1117/12.2307917.

6. Beaucamp A, Simon P, Charlton P, King C, Matsubara A, Wegener $\mathrm{K}$. Brittle-ductile transition in shape adaptive grinding (SAG) of SiC aspheric optics. Int J Mach Tools Manuf. 2017;115:29-37. http://dx.doi.org/10.1016/j.ijmachtools.2016.11.006.

7. Horvath N, Honeycutt A, Davies M A. Grinding of additively manufactured silicon carbide surfaces for optical applications. CIRP Ann. 2020;69:509-12. http://dx.doi.org/10.1016/j. cirp.2020.04.079.

8. Rodrigues AC, Souza RNF, Galisa OF, França TV, Bianchi EC, Foschini CR. Effect of grinding parameters on the surface finish of advanced ceramics. Matéria (Rio J.). 2016;21:1012-20. http://dx.doi.org/10.1590/s1517-707620160004.0093.

9. Venkatesh VC, Izman S. Precision engineering. New Delhi: Tata McGraw-Hill; 2007.

10. Mamalis AG, Kundrak J, Gyani K, Horvath M. On the precision grinding of advanced ceramics. Int J Adv Manuf Technol. 2002;20:255-8. http://dx.doi.org/10.1007/s001700200150.

11. Arif M, Rahman M, San WY. Ultra precision ductile mode machining of glass by micromilling process. J Manuf Process. 2011;13:50-9. http://dx.doi.org/10.1016/j.jmapro.2010.10.004.

12. Malkin S, Hwang T W. Grinding mechanisms for ceramics. CIRPAnn. 1996;45:569-80. http://dx.doi.org/10.1016/S00078506(07)60511-3.

13. Bifano TG, Fawcett SC. Specific grinding energy as an inprocess control variable for ductile-regime grinding. Precis Eng. 1991;13:256-62. http://dx.doi.org/10.1016/0141-6359(91)90003-2.

14. Zhong ZW. Ductile or partial ductile mode machining of brittle materials. Int J Adv Manuf Technol. 2003;21:579-85. http:// dx.doi.org/10.1007/s00170-002-1364-5.
15. Blackley WS, Scattergood RO. Ductile-regime machining model for diamond turning of brittle materials. Precis Eng. 1991;13:95103. http://dx.doi.org/10.1016/0141-6359(91)90500-I.

16. Meng B, Qiu P, Xu S. Influence of microstructure on the diamond-machinability of hot-pressed silicon carbide: A molecular dynamics study. Ceram Int. 2019;45:22872-9. http:// dx.doi.org/10.1016/j.ceramint.2019.07.330.

17. Sanjay A. Optimizing machining parameters to combine high productivity with high surface integrity in grinding silicon carbide ceramics. Ceram Int. 2016;42:6244-62. http://dx.doi. org/10.1016/J.CERAMINT.2016.01.008.

18. Bifano TG, Dow TA, Scattergood RO. Ductile-regime grinding: a new technology for machining brittle materials. J Eng Ind. 1991;113:184-9. http://dx.doi.org/10.1115/1.2899676.

19. Bifano TG, Dow TA, Scattergood RO. Ductile-regime grinding of brittle materials: experimental results and the development of a model. In: SPIE of the 32nd Annual International Technical Symposium on Optical and Optoelectronic Applied Science and Engineering; 1988; San Diego, CA, USA. Proceedings. USA: SPIE; 1988. Vol. 0966, p. 108-15. http://dx.doi.org/10.1117/12.948055.

20. Jacobs SD, Golini D, Hsu Y, Puchebner BE, Strafford D, Prokhorov IV, et al. Magnetorheological finishing: a deterministic process for optics manufacturing. In: International Conference on Optical Fabrication and Testing; 1995; Tokyo, Japan. Proceedings. Japan, 1995. Vol. 2576, p. 372-92. http://dx.doi. org/10.1117/12.215617.

21. Agarwal S, Paruchuri VR. Experimental investigation of surface/ subsurface damage formation and material removal mechanisms in SiC grinding. Int J Mach Tools Manuf. 2008;48:698-710. http://dx.doi.org/10.1016/j.ijmachtools.2007.10.013.

22. Pierson HO. Handbook of refractory carbides and nitrides, properties, characteristics, processing and applications. New Jersey: Noyes Publications; 1996.

23. Gu W, Yao Z, Li H. Investigation of grinding modes in horizontal surface grinding of optical glass BK7. J Mater Process Technol. 2011;21:1629-36. http://dx.doi.org/10.1016/j. jmatprotec.2011.05.006.

24. Solhtalab A, Adibi H, Esmaeilzare A, Rezaei SM. Cup wheel grinding-induced subsurface damage in optical glass BK7: an experimental, theoretical and numerical investigation. Precis Eng. 2019;57:162-75. http://dx.doi.org/10.1016/j. precisioneng.2019.04.003. 